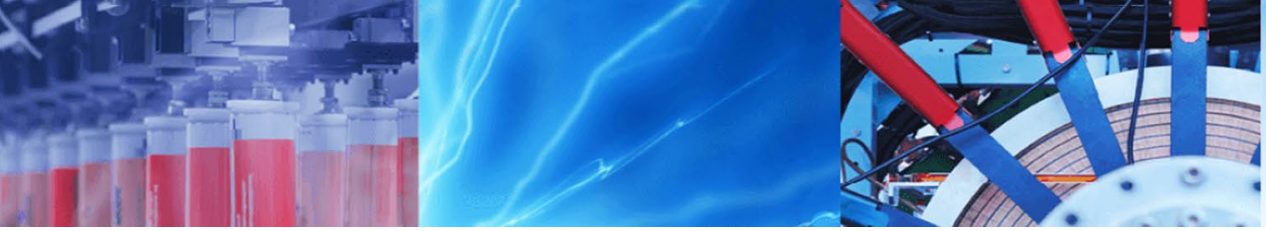

Research Article

\title{
Prediction of material properties by 2-D numerical simulation of carbonization process of carbon-carbon composites
}

\author{
Ravindra Kumar ${ }^{1} \cdot$ N. L. Ravikumar² $\cdot$ Chinmay Pandya $^{2} \cdot$ Kamal K. Kar $^{1,2} \cdot$ Kinshuk Dasgupta $^{3}$
}

(c) Springer Nature Switzerland AG 2019

\begin{abstract}
The degradation of polymer matrix composite material during carbonization and the processing temperature are some important deciding factors to evaluate the performance of carbon-carbon composite (CC) for the targeted applications. In present study, the carbonization of material at the temperature range of $1200-1500^{\circ} \mathrm{C}$ is considered as a critical step for understanding the material performance, as it is essential for the progress in the processing of CCs. The heat, mass and momentum transport equations are used with weight loss kinetics to develop a numerical simulation model for the carbonization process. Afterward, to solve the governing equations, a 2-D finite difference method (FDM) is employed. Using material properties, the developed numerical model predicts the distribution of pressure, porosity, density, specific heat, thermal conductivity as a function of surface temperature for square samples of various thicknesses at different heating rates. The comparisons of the results of the 2-D model are carried out with results of 1-D FDM model published earlier.
\end{abstract}

Keywords Carbon-carbon composites · Carbonization · Degradation · Porosity · Specific heat · Simulation · Thermal conductivity

\section{Introduction}

Carbon-carbon composite (CCs) are the composite materials in which carbon fiber reinforcements are embedded in the graphitic carbon matrix. The CCs are preferably employed in high-performance structural parts such as rocket nose cone, wing leading edges of the space shuttle, aircraft and racing car braking shoes pads etc., owing to low density, high specific strength and specific modulus, high ablation resistance, low coefficient of thermal expansion and exceptionally high thermal stability (can withstand more than $3000^{\circ} \mathrm{C}$ in the inert environments) [1-3].

The CCs are usually obtained after three stage processing: In the first stage, the polymer matrix composites (PMCs) are fabricated by impregnation of liquid polymer resin, for instance thermoset polymer resin (epoxy or phenolic), or thermoplastic polymer resin (pitch, coke) into carbon fiber or textile then curing under application of specific temperature and pressure. In the second stage, polymer matrix composite is converted into pyrolytic-carbon matrix composite through high temperature pyrolysis at controlled heating rate followed by densification cycle either via resin re-impregnation-pyrolysis route or chemical vapour infiltration (CVI) with moderate pressure of hydrocarbon gases or liquids in the carbon fiber preform [1]. In the third stage, graphitization of porous carbon matrix composite is carried out in an inert atmosphere [1]. The CCs obtained after carbonization or graphitization exhibit porous structure with inferior mechanical properties and low density [4, 5].

The carbonization of PMCs from room temperature to $1500{ }^{\circ} \mathrm{C}$ that transforms it into porous and amorphous

Kamal K. Kar, kamalkk@iitk.ac.in; Ravindra Kumar, ravindra.che@gmail.com; N. L. Ravikumar, nlriitkmsp@gmail.com; Chinmay Pandya, panda.cpiitkmsp@gmail.com; Kinshuk Dasgupta, kdg@barc.gov.in | 1 Advanced Nanoengineering Materials Laboratory, Materials Science Programme, Indian Institute of Technology Kanpur, Kanpur, UP 208016, India. ${ }^{2}$ Advanced Nanoengineering Materials Laboratory, Department of Mechanical Engineering, Indian Institute of Technology Kanpur, Kanpur, UP 208016, India. ${ }^{3}$ Materials Group, Bhabha Atomic Research Centre, Mumbai 400085, India. 
carbon is considered as a crucial step in the fabrication of carbon-carbon composites (CCs). During the heating of the composite structure in the presence of inert gas, the gradients of the pressure and temperature in the laminate are developed. As the temperature of the furnace increases, the composite material absorbs energy from its surroundings and further heating results degradation of the stuff that lead to the removal of volatiles and weight loss from the composite materials. Consequently, several micro and macro-structural changes occur such as the development of thermal stresses, the formation of voids, cracks, warps, and delamination in the matrix that lead to decrease in the density, mechanical and thermal properties of the composites [6-10].

Therefore, the formation of pressure and temperature gradients during carbonization of PMCs need to be minimized. It can be accomplished by regulating the heating rate that further helps to govern the speed of gas evolution owing to degradation reactions. However, the slow heating rate increases the processing time which further results in high processing cost $[10,11]$. Hence for the fabrication of CCs, the carbonization process at the initial stage is considered as the rate deciding step. Thus, to enhance the carbonization process, the realization of this step is necessary.

The carbonization behavior of PMCs have been studied either by experimental analysis or by developing several empirical models. In the preliminary studies, special attention is given to the variation of mechanical properties of CCs with respect to changes in heating rates [11-14]. Furthermore in the models, the carbonization behavior has been studied either separately or along with other factors such as weight loss kinetics [4, 5], pure chemical kinetics $[15,16]$, Brownian motion technique [17], ablative characteristics [18-20], response to fire [21], interfacial thermal stresses [22], thermal expansion coefficients [23], thermal conductivity [24], estimation of cracks, displacement and stresses, and using very simple geometries or assumptions to solve heat, mass and momentum transport problems separately [3, 25-27].

Recently only few researchers have tried to predict some important properties of carbon-carbon composites at the initial stage of carbonization process using simulation methods of such as shrinkages in thickness, stress and cracks development with increasing the carbonization temperature using numerical simulation methods. They have also predicted the variation of pressure, temperature, porosity and other material properties such as specific heat and thermal conductivities inside samples during the processing of CCs with respect to processing time. However, these studies are not able to explain the effect of heating rate and size of the composite on the various properties of composites at the initial stage of carbonization of $2 \mathrm{D}$ composite using any model. Hence in the present manuscript a comprehensive 2-D numerical simulation model is built to analyze the carbonization process of CCs. The effects of heating rate and composite size on the pressure, porosity, density, specific heat and thermal conductivity distributions with respect to surface temperature are investigated.

\section{Equations governing the carbonization process}

\subsection{Model formulation}

The initial steps and assumptions of one dimensional (1-D) model given by Nam and Seferis [3] are taken into consideration for analysis of carbonization process used for making CCs. For the numerical simulation of the 2-D control volume, the final governing equations $[3,26,27]$ can be given as follows:

The final energy equation can be written as $[3,26,27]$ :

$$
\begin{aligned}
((1 & \left.-\phi) \mathrm{D}_{\mathrm{s}} c_{\mathrm{s}}+\phi \mathrm{D}_{\mathrm{g}} \mathrm{c}_{\mathrm{g}}\right) \times\left(\frac{\partial \theta}{\partial \mathrm{t}}+V_{x} \frac{\partial \theta}{\partial \mathrm{x}}+V_{\mathrm{y}} \frac{\partial \theta}{\partial \mathrm{y}}\right) \\
= & \kappa_{\mathrm{x}} \frac{\partial^{2} \theta}{\partial \mathrm{x}^{2}}+\kappa_{\mathrm{y}} \frac{\partial^{2} \theta}{\partial \mathrm{y}^{2}}+\Delta \mathrm{H}
\end{aligned}
$$

where $\phi, \mathrm{D}_{\mathrm{s}^{\prime}} \mathrm{D}_{\mathrm{g}^{\prime}} \mathrm{c}_{\mathrm{s}^{\prime}} \mathrm{c}_{\mathrm{g}^{\prime}} \theta, \mathrm{t}, V_{\mathrm{x}^{\prime}}, V_{\mathrm{y}^{\prime}} \mathrm{K}_{\mathrm{x}^{\prime}} \mathrm{K}_{\mathrm{y}}$ and $\Delta \mathrm{H}$ are the porosity, density of solid, density of gas, heat capacity of solid, heat capacity of gas, absolute temperature, time, gas velocity in $\mathrm{x}$-direction, gas velocity in $\mathrm{y}$-direction, thermal conductivity of composites in $x$-direction, thermal conductivity of composites in y-direction, and heat of reaction, respectively.

The final momentum equations can be represented as $[3,26,27]$ :

$V_{x}=-\frac{k_{\mathrm{g}, \mathrm{x}}}{\eta_{\mathrm{g}}} \frac{\partial \mathrm{P}}{\partial \mathrm{x}} \quad$ and $\quad V_{\mathrm{y}}=-\frac{k_{\mathrm{g}, \mathrm{y}}}{\eta_{\mathrm{g}}} \frac{\partial \mathrm{P}}{\partial \mathrm{y}}$

where $k_{g, x^{\prime}} \mathrm{k}_{\mathrm{g}, \mathrm{y},} \eta_{\mathrm{g}}, \mathrm{P}, V_{\mathrm{x}}$ and $V_{\mathrm{y}}$ are the gas permeability in the $x$-direction, gas permeability in the $y$-direction, gas viscosity, pressure, velocity in $\mathrm{x}$-direction and speed in the $y$-direction, respectively. The derivation of Eq. (2) can be found in [27].

The final pressure equation can be written as $[3,26,27]$ :

$$
\frac{\partial\left(\phi \frac{\mathrm{P}}{\mathrm{R} \theta}\right)}{\partial \mathrm{t}}+\frac{\partial\left(-\frac{\mathrm{k}_{\mathrm{g}, \mathrm{x}}}{\eta_{\mathrm{g}}} \frac{\mathrm{P}}{\partial \mathrm{x}} \frac{\mathrm{P}}{\mathrm{R} \theta}\right)}{\partial \mathrm{x}}+\frac{\partial\left(-\frac{\mathrm{k}_{\mathrm{g}, \mathrm{y}}}{\eta_{\mathrm{g}}} \frac{\partial \mathrm{P}}{\partial \mathrm{y}} \frac{\mathrm{P}}{\mathrm{R} \theta}\right)}{\partial \mathrm{y}}=\delta
$$


$\frac{\partial(\alpha \mathrm{P})}{\partial \mathrm{t}}-\frac{\partial\left(\beta \frac{\partial \mathrm{P}}{\partial \mathrm{x}}\right)}{\partial \mathrm{x}}-\frac{\partial\left(\gamma \frac{\partial \mathrm{P}}{\partial \mathrm{y}}\right)}{\partial \mathrm{y}}=\delta$

where

$\alpha=\frac{\phi}{\mathrm{RT}}, \quad \beta=\frac{k_{\mathrm{g}, \mathrm{x}}}{\eta_{\mathrm{g}}} \frac{\mathrm{P}}{\mathrm{R} \theta} \quad$ and $\quad \gamma=\frac{k_{\mathrm{g}, \mathrm{y}}}{\eta_{\mathrm{g}}} \frac{\mathrm{P}}{\mathrm{R} \theta}$

$\mathrm{R}$ and $\delta$ are the universal gas constant and source term, respectively. Other terms have the same meaning as said above. The derivation of Eq. 3 is given in [27].

The boundary conditions employed were as per the heating environment inside the furnace (inert gas heating was used here). The square isotropic composite made of phenolic resin and $8 \mathrm{H}$ satin $\mathrm{T}-300$ carbon fabric was placed on the bottom surface of the furnace. The base and top surfaces including sides of the composite laminate were heated due to exposure in the furnace atmosphere. To keep the pressure constant ( 1 atmosphere) during the entire carbonization process, the inert gas was continuously supplied inside the furnace.

A numerical simulation was carried out using the Dirichlet conditions on the bottom surface of the composite laminate having the square cross-section (2-D geometry). The lumped capacitance method was used to determine the inside surface temperature of the furnace. The same conditions were also applied to the top surface since the gas heating was done inside the furnace surface. As the heat transfer occurred mainly in convective mode on the side surfaces of the laminate, therefore, convective conditions were used. Since the gas pressure inside the furnace was kept at $\sim 1$ atmosphere hence the pressure exerted on the laminate surface was assumed to be the same ( 1 atmosphere).

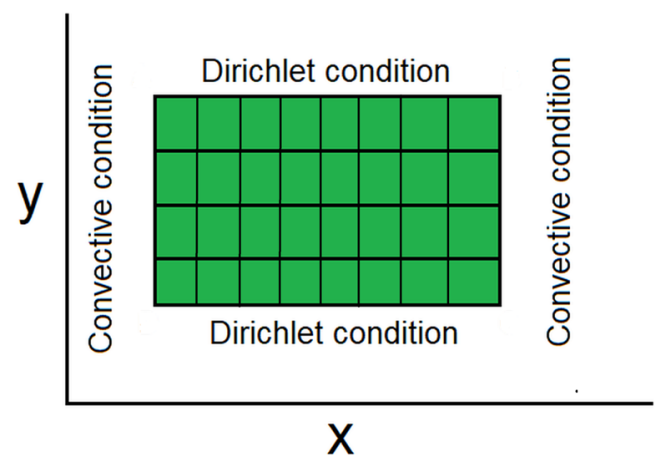

Fig. 1 Schematic of 2-D laminate (boundary conditions are also mentioned here)
Figure 1 exhibits 2D laminates. The boundary conditions are also represented here. The boundary conditions for the temperature of the laminate can be written as

Initial boundary conditions:

$\theta=\theta_{o}$ at $\mathrm{t}=0$ over $0<\mathrm{x}<1 \& 0<\mathrm{y}<1$

Dirichlet conditions:

$\theta=\theta_{\mathrm{h}}$ for $\mathrm{y}=0 \& \mathrm{y}=\mathrm{l}, \mathrm{t}>0$

Convective conditions:

$-\kappa_{\mathrm{x}} \frac{\partial \theta}{\partial \mathrm{x}}=\mathrm{h}\left(\theta-\theta_{\mathrm{a}}\right)$ for $\mathrm{x}=0 \& \mathrm{l}, \mathrm{t}>0$

where $\theta_{\mathrm{h}}$ and $\theta_{\mathrm{a}}$ are the furnace heating temperature and the furnace atmosphere temperature, respectively, $h$ is the convective heat transfer coefficient.

The boundary conditions for pressure can be expressed as

Initial pressure conditions:

$\mathrm{P}=\mathrm{P}_{\mathrm{o}}$ at $\mathrm{t}=0$ over $0<\mathrm{x}<\mathrm{I} \& 0<\mathrm{y}<\mathrm{I}$

$\mathrm{P}=\mathrm{P}_{\mathrm{o}}$ at $\mathrm{t}>0, \mathrm{x}=0 \& \mathrm{x}=1$

Neumann conditions:

$\frac{\partial \mathrm{P}}{\partial y} \& \frac{\partial \mathrm{P}}{\partial y}=0$ for $\mathrm{y}=0 \& \mathrm{y}=\mathrm{l}, \mathrm{t}>0$

\subsection{Evaluation of material properties}

The evaluation of material properties is the most significant job to understand the carbonization process and to get a solution to solve a material problem. During the carbonization, the matrix weight decreases due to the removal of volatile matters or gases in the degradation process consequently the properties of the composites vary. The aggregated effect on material properties as a result of the variation in temperature and degradation of the matrix is demonstrated in the next paragraphs.

In the present study, the weight loss of phenolic resin (cured with 1 wt\% para-toluene sulphonic acid) with increasing the temperature was measured with the help of thermogravimetric analysis. A method given by Nam and Seferis [3] was used to establish the degradation kinetics of phenolic resin. Weight loss behavior of cured phenolic resin was studied under the nitrogen atmosphere at a heating rate of $2^{\circ} \mathrm{C} \min ^{-1}$ as shown in Fig. 2 .

To determine the variation in the porosity of the composite owing to the degradation of the matrix, the following correlation given by Nam and Seferis [3] was used:

$\phi=\phi_{0}+0.225 \psi$ 


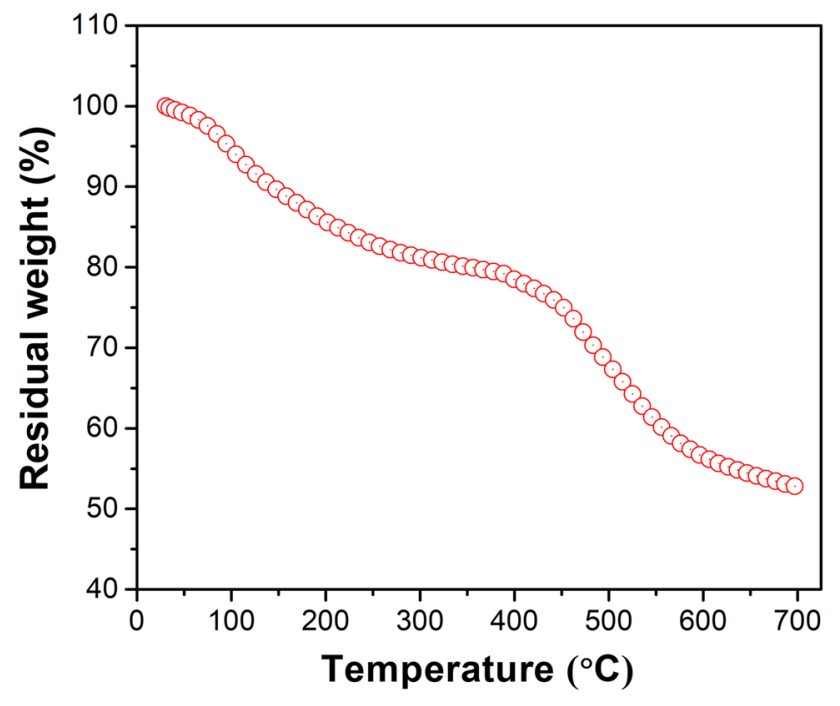

Fig. 2 Residual weight versus temperature curve for cured phenolic resin

where $\phi_{0}, \phi$ and $\psi$ were the initial porosity (assume 0.01, [27]), final porosity after matrix degradation and the degree of matrix degradation, respectively.

Moreover, the method given by Nam and Seferis [3] was also employed to calculate the average molecular weight of the gases evolved during matrix degradation and the viscosity of gases was estimated considering following assumptions: (i) viscosity changes with respect to temperature only, (ii) carbon dioxide is considered as the major part out of the evolve gases.

The change in the viscosity of carbon dioxide gas with respect to the temperature was calculated using Eqs. (12) and (13) given by Broomley and Wilke [28].

$\eta_{\mathrm{cp}}=\frac{0.000423 \sqrt{\mathrm{M}_{\mathrm{w}}} \mathrm{P}_{\mathrm{c}}^{2 / 3}}{\theta_{\mathrm{c}}^{1 / 6}} \mathrm{f}\left(\frac{\kappa \theta}{\xi}\right)$

$f\left(\frac{\kappa \theta}{\xi}\right)=1.058 \theta_{r}^{0.645}-0.262\left(1.9 \theta_{r}\right)^{-0.9 \log \left(1.9 \theta_{r}\right)}$

where $\eta_{\mathrm{cp}}, \mathrm{M}_{\mathrm{w}^{\prime}} \mathrm{P}_{\mathrm{c}^{\prime}} \theta_{\mathrm{c}^{\prime}}$ and $\theta_{\mathrm{r}}$ were the viscosity at critical temperature and pressure, molecular weight ( $\mathrm{g} / \mathrm{mole})$, critical pressure (atmosphere), critical temperature $(\mathrm{K})$, and reduced temperature (ratio of actual temperature to the critical temperature), respectively.

The gas permeability in the composites was measured by the relation as given by Nam and Seferis [3]

$k_{g}=\frac{d_{f}^{2} \phi^{3}}{16 k^{\prime}(1-\phi)^{2}}$ where $k_{g}, d_{f}, \phi$ and $k^{\prime}$ were gas permeability, fiber diameter, porosity and Kozeny constant, respectively. The fiber diameter was used here as $7 \mu \mathrm{m}$. The values of Kozeny constants used here were 0.18 and 2.11 for the in-plane and the through thickness cases, respectively.

The density of composites was calculated using following relation (the rule of mixture)

$D_{s}=D_{f} v_{f}+D_{m} v_{m}$

where $D_{s}, D_{f}, v_{f}$ and $v_{m}$ were the density of composite, density of fiber (taken as $2 \mathrm{~g} \mathrm{~cm}^{-3}$ ), the density of matrix (taken as $1.3 \mathrm{~g} \mathrm{~cm}^{-3}$ ), volume fraction of fiber in composites and volume fraction of the matrix in composites, respectively.

The degradation of the matrix occurs during the carbonization of the composites that results in variation in fiber volume fraction. Therefore, the estimation of the fiber volume fraction at various stages of degradation is considered as very important and calculated using the following equation:

$v_{f}=\frac{r(1-\phi)}{(0.433-0.433 \psi+r)}$

where $r$ is the ratio of matrix density to fiber density. Furthermore, the specific heat of the composite was determined using the rule of the mixture as given by Mottram and Taylor $[29,30]$

$c_{\mathrm{s}}=\mathrm{c}_{\mathrm{f}} \mathrm{v}_{\mathrm{f}}+\mathrm{c}_{\mathrm{m}} \mathrm{v}_{\mathrm{m}}$

where $c_{s}, c_{f}, c_{m}, v_{f}$ and $v_{m}$ were heat capacity of the composite, heat capacity of the fiber, heat capacity of the matrix, volume fraction of fiber and volume fraction of matrix, respectively.

The heat capacity of fiber can be determined as $[29,30]$

$$
\begin{aligned}
& \mathrm{C}_{\mathrm{f}}=415.8+4.361 \theta-0.7112 \times 10^{-2} \theta^{2}+\frac{0.5332 \times 10^{6}}{\theta^{2}} \\
& \text { for } \theta<400{ }^{\circ} \mathrm{C}
\end{aligned}
$$

$=1.52371 \cdot(\theta+273.15)$, for $400{ }^{\circ} \mathrm{C}<\theta<727^{\circ} \mathrm{C}$

$=1.656 \cdot(\theta+273.15), \quad$ for $727^{\circ} \mathrm{C}<\theta<1400^{\circ} \mathrm{C}$

The heat capacity of matrix can be represented as $[29,30]$

$c_{m}=-189.9+27 \theta-0.06342 \theta^{2}+\frac{0.1796 \times 10^{7}}{\theta^{2}}, \quad$ for $\theta<230^{\circ} \mathrm{C}$

$=2.7 \mathrm{~J} \mathrm{~g}^{-1} \mathrm{~K}^{-1}$, for temperature $\theta>230^{\circ} \mathrm{C}$

In 2-D composites, the thermal conductivity was higher along fiber direction than its perpendicular direction. The thermal conductivity of 2D composites perpendicular to fiber direction was determined using the following 
relation of Bruggeman model given by Mottaram and Tay-

lor $[29,30]$ accounting porosity.

$$
\frac{\kappa_{\mathrm{y}}^{\phi=0}}{\kappa_{\mathrm{m}}}=\left[\frac{\left(\left(1-v_{\mathrm{f}}^{\phi=0}\right)\left(\frac{\kappa_{\perp f}}{\kappa_{\mathrm{m}}}-1\right)^{2}+4 \frac{\kappa_{\perp f}}{\kappa_{\mathrm{m}}}\right)^{1 / 2}-\left(1-v_{\mathrm{f}}^{\phi=0}\right)\left(\frac{\kappa_{\perp f}}{\kappa_{\mathrm{m}}}-1\right)}{2}\right]^{2}
$$

$$
\frac{\kappa_{y}}{\kappa_{\mathrm{m}}}=\frac{\kappa_{\mathrm{y}}^{\phi=0}}{\kappa_{\mathrm{m}}}(1-\phi)^{\frac{x+1}{x}}
$$

where $X$ was the shape factor for discontinuous phase (presence of porosity) in perpendicular to the heat flow (1 for cylindrical pores), $\kappa_{\perp f}$ was the thermal conductivity of fiber in transverse direction $\left(0.024 \mathrm{~W} \mathrm{~cm}^{-1} \mathrm{~K}^{-1}\right.$ at $\left.140^{\circ} \mathrm{C}\right), \kappa_{\mathrm{m}}$ was the thermal conductivity of matrix $\left(0.0029 \mathrm{~W} \mathrm{~cm}^{-1} \mathrm{~K}^{-1}\right.$ at $29^{\circ} \mathrm{C}$ ).

The thermal conductivity in the plane of fiber $\left(\mathrm{k}_{\mathrm{x}}\right)$ was estimated using following equations given by Mottram and Taylor [29, 30].

$\kappa_{\mathrm{x}}=\frac{1}{2} \kappa_{\mathrm{x} 1}+\frac{1}{2} \kappa_{\mathrm{y}}$

$\kappa_{\mathrm{x} 1}=\kappa_{\mathrm{lf}} \mathrm{v}_{\mathrm{f}}+\kappa_{\mathrm{m}} \mathrm{v}_{\mathrm{m}}$

where $\mathrm{K}_{\mathrm{y}}$ and $\mathrm{K}_{\mathrm{lf}}$ were the thermal conductivity of fiber in the transverse direction and longitudinal direction $\left(0.03 \mathrm{~W} \mathrm{~cm}^{-1} \mathrm{~K}^{-1}\right.$ at $\left.350^{\circ} \mathrm{C}\right)$, respectively.

\subsection{Numerical methods}

To solve the pressure and energy equations, the Backward Time Centred Space (BTCS) formulation was used that resulted in first order time accuracy but second-order space accuracy. The governing equations were solved in a semi-implicit way, i.e., the values of the coefficients of equations and the source terms of the equations were taken from the time steps, and the equations were solved implicitly. For a specific temperature distribution, the pressure distribution was calculated using Eq. (3). Then gas velocity was obtained directly using pressure value in Eq. (2). After that, the temperature was calculated with the help of Eq. (1) using pressure and velocity profiles.

Uniform grids with $\mathrm{N} \times \mathrm{M}$ nodes (where $\mathrm{N}$ and $\mathrm{M}$ are the equidistance points in the horizontal and vertical direction, respectively) on domain were considered for the discretization in space. Each internal block possessed the internal nodes at the center while the side block had the nodes at the boundary, but the corner block owned their nodes at the vertices of the domain.

\section{Results and discussions}

The composites were made by phenolic resin, and $8 \mathrm{H}$ satin T-300 carbon fabric and their carbonization behavior were studied at three different heating rates of 2,5 and $7{ }^{\circ} \mathrm{C} \mathrm{min}-1$. The sizes of samples were taken as $1 \times 1$, $2 \times 2,4 \times 4$ and $6 \times 6 \mathrm{~cm}^{2}$. The simulation was carried out by running a code developed in $C$ language using the Linux Operating System. For simulation, the initial conditions of pressure and temperature were taken as $\theta(x, y, 0)=300 \mathrm{~K}$ and $P(x, y, 0)=1.013$ bar. Moreover, the Kozeny-Carman model was considered for $\mathrm{Kp}-\phi$ relation while the Buggermann model was considered for $\mathrm{K}_{\mathrm{x}}-v_{f}$ and $\mathrm{K}_{\mathrm{y}}-v_{\mathrm{f}}$ relation. The code was performed in both $X$ and $Y$ directions using grid spacing of $0.05,0.1,0.1$ and $0.15 \mathrm{~cm}$, respectively and time step was taken as $d t=0.01 \mathrm{~s}$ in all cases. The results obtained were plotted using Tecplot software to get the maximum values of pressure, surface temperature, porosity, density, composite specific heat and thermal conductivity. In order to verify the validity of code, the model was moved to the steady and unsteady conditions for constant porosity porous media with fixed flow rate.

In order to understand the structural changes, occur during carbonization process, the profiles of the various parameters or characteristics such as pressure, temperature, porosity, etc. were studied over the temperature range of $25-1400{ }^{\circ} \mathrm{C}$. The heating rate was varied from 2 , 5 and $7{ }^{\circ} \mathrm{C} \mathrm{min}^{-1}$. In addition to these variables the size of laminates were varied from $1 \times 1$ to $2 \times 2,4 \times 4$ and $6 \times 6 \mathrm{~cm}^{2}$. Few representative plots for pressure, temperature, porosity and specific heat at the temperature of $305^{\circ} \mathrm{C}$ (time: $8400 \mathrm{~s}$ ) are shown in Fig. 3. Here the heating rate was kept at $2{ }^{\circ} \mathrm{C} \mathrm{min}^{-1}$, and the size of the sample was taken as $1 \times 1 \mathrm{~cm}^{2}$. As the carbonization temperature reaches at $305^{\circ} \mathrm{C}$ (time: $8400 \mathrm{~s}$ ), the pressure is building up inside the composite as shown in Fig. 3a. This temperature is considered as the first stage degradation temperature of phenolic resin [29]. Consequently, as the temperature increases, the evolved gases do not get sufficient space to flow out and therefore accumulate at the center region as shown in Fig. 3b. Herein the porosity of the composite is found low as depicted in Fig. 3c. Though porosity and 

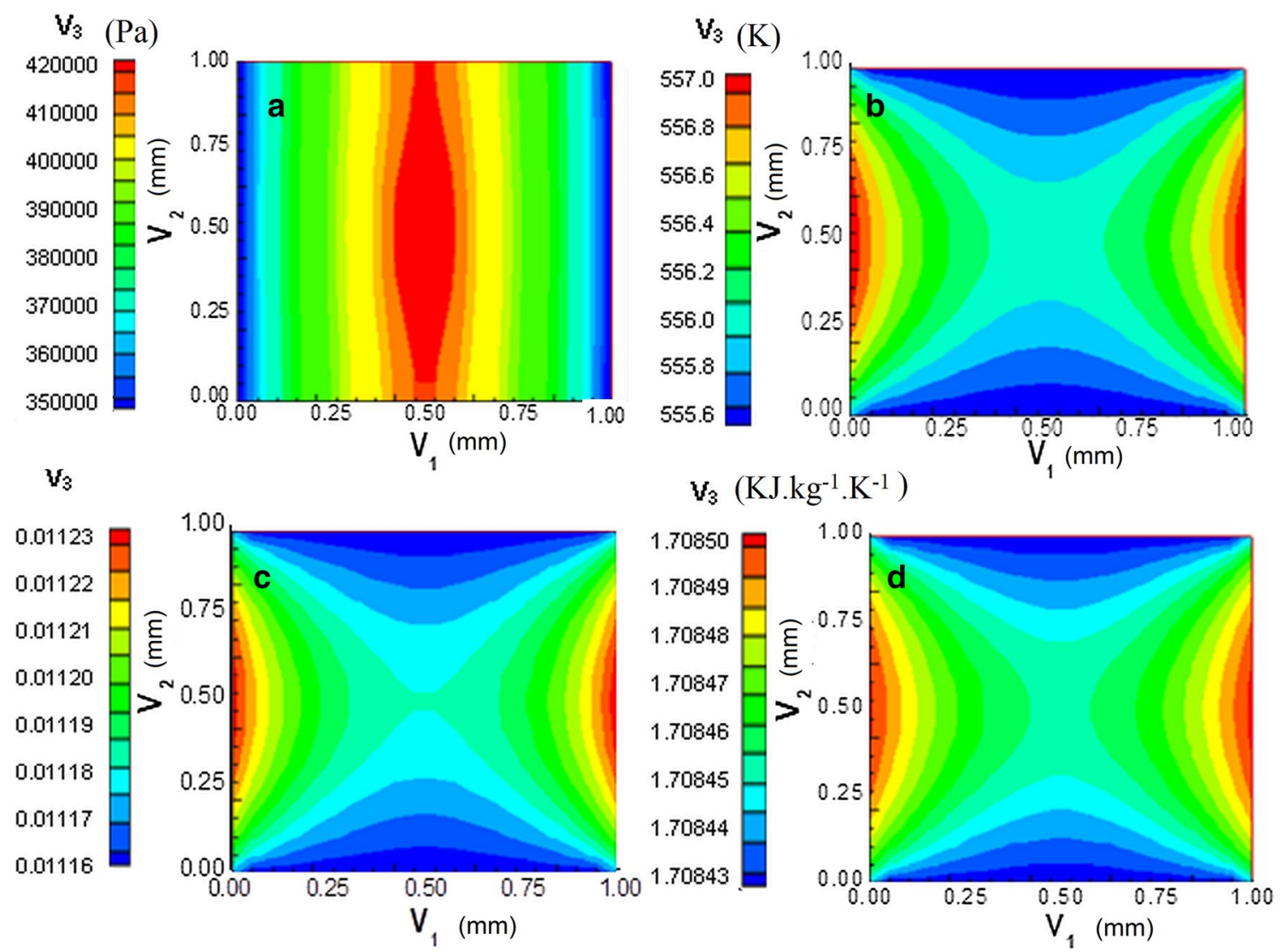

Fig. 3 Profiles of a pressure $\mathbf{b}$ temperature $\mathbf{c}$ porosity and $\mathbf{d}$ specific heat inside the domain during processing of $1 \times 1 \mathrm{~cm}{ }^{2} \mathrm{CCs}$ at $8400 \mathrm{~s}$ (temperature: $305^{\circ} \mathrm{C}$ )

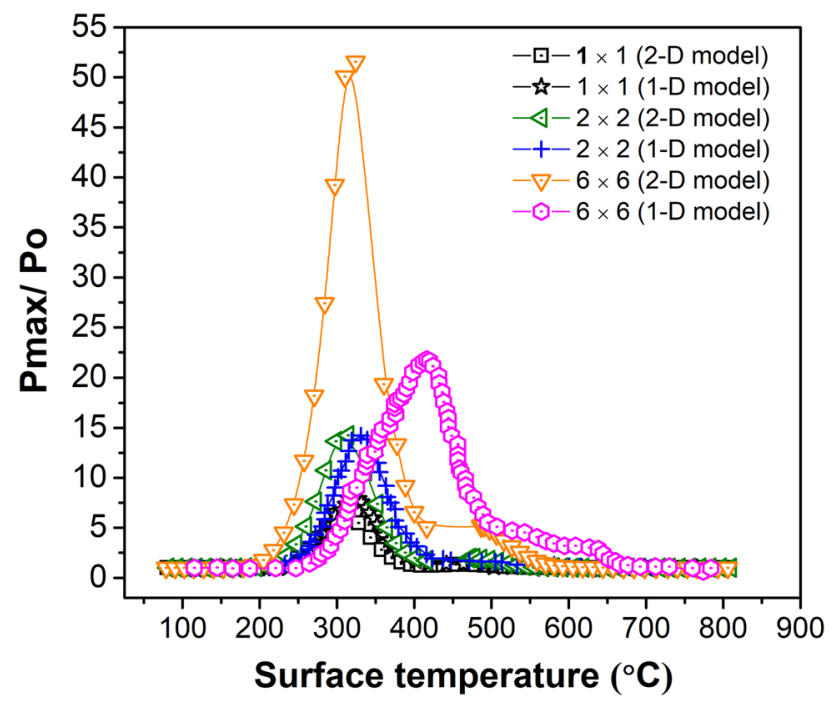

Fig. 4 Variation of internal pressure as a function of surface temperature for several sizes of samples at the heating rate of $2{ }^{\circ} \mathrm{C} \mathrm{min}^{-1}$ and comparison of the newly proposed model with 1-D FDM model proposed by Nam and Seferis [3] volume fraction of the fibers both affect the specific heat variation inside the domain, however, the porosity is low at this temperature as shown in Fig. 3d, therefore the specific heat at this stage, entirely depends on the volume fraction of the fibers.

Figure 4 shows the pressure buildup with respect to surface temperature of the laminate. The maximum pressure is developed at the first stage degradation temperature of the phenolic resin, i.e., $310^{\circ} \mathrm{C}$. This consequence is because of the entrapment of decomposed gases within the matrix, as the porous composites at this stage have low porosity and the permeability. At $8550 \mathrm{~s}$ (i.e., $310^{\circ} \mathrm{C}$ ), the internal pressure is reached to a maximum level as demonstrated in Figs. 4 and 5a. Herein, the temperature is also started to increase at the center as reflected from Fig. 5b. Furthermore, it can also be seen that the maximum pressure build-up depends upon the size of the laminate (Fig. 4). A comparison is carried out of the maximum pressure buildup inside the composite with respect to surface temperature (for heating rate of $2{ }^{\circ} \mathrm{C} \mathrm{min}^{-1}$ ) to the results of 1-D FDM model in which Gear method given by Nam 

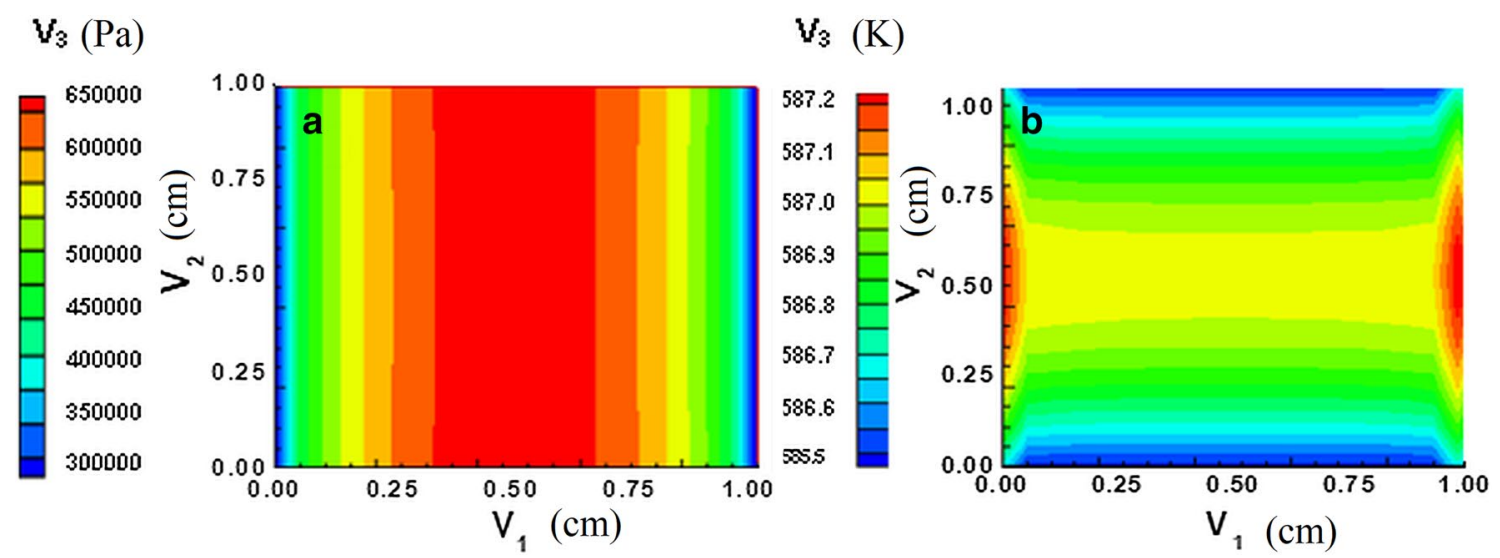

Fig. 5 Profiles of $\mathbf{a}$ pressure and $\mathbf{b}$ temperature inside the domain during processing of $1 \times 1 \mathrm{~cm}^{2}$ sample at $8550 \mathrm{~s}$ (temperature $=310^{\circ} \mathrm{C}$ )
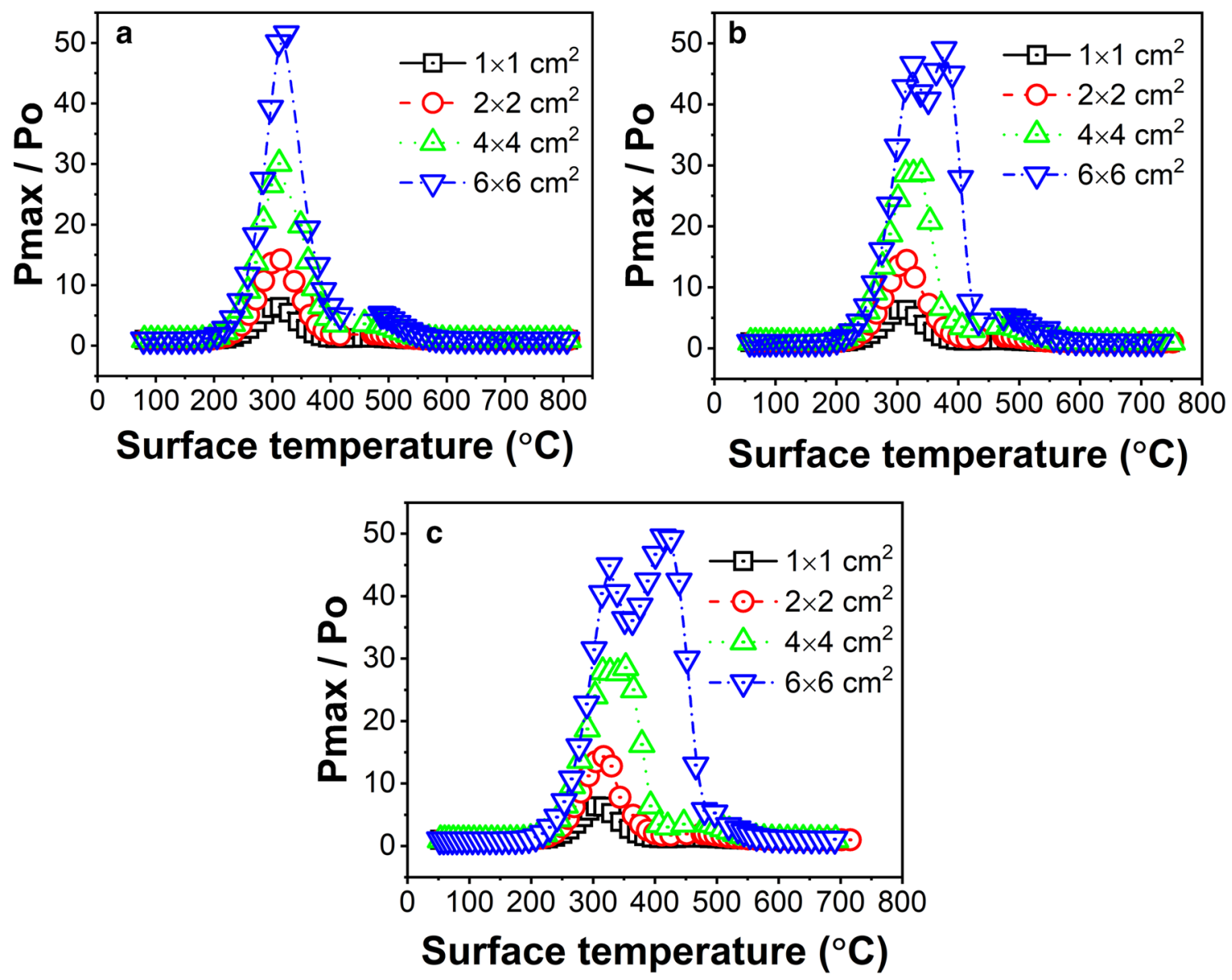

Fig. 6 Variation of internal pressure as a function of surface temperature for several sizes of samples at the heating rate of: a 2, b 5 and $\mathbf{c}$ $7^{\circ} \mathrm{C} \mathrm{min}^{-1}$

and Seferis [3] is used (Fig. 4). It can be seen that the results (maximum pressure buildup) of composites with size of $1 \times 1$ and $2 \times 2 \mathrm{~cm}^{2}$ are nearly matched with the published result of 1-D FDM model analysis. But the composite with $6 \times 6 \mathrm{~cm}^{2}$ sample size exhibit higher maximum pressure buildup and the point of maximum pressure buildup is somewhat before the 1-D model. This may be caused due to the difference in the boundary conditions of the temperature and the initial material properties. Moreover, in 1-D FDM model, the surface of the composite sample was 

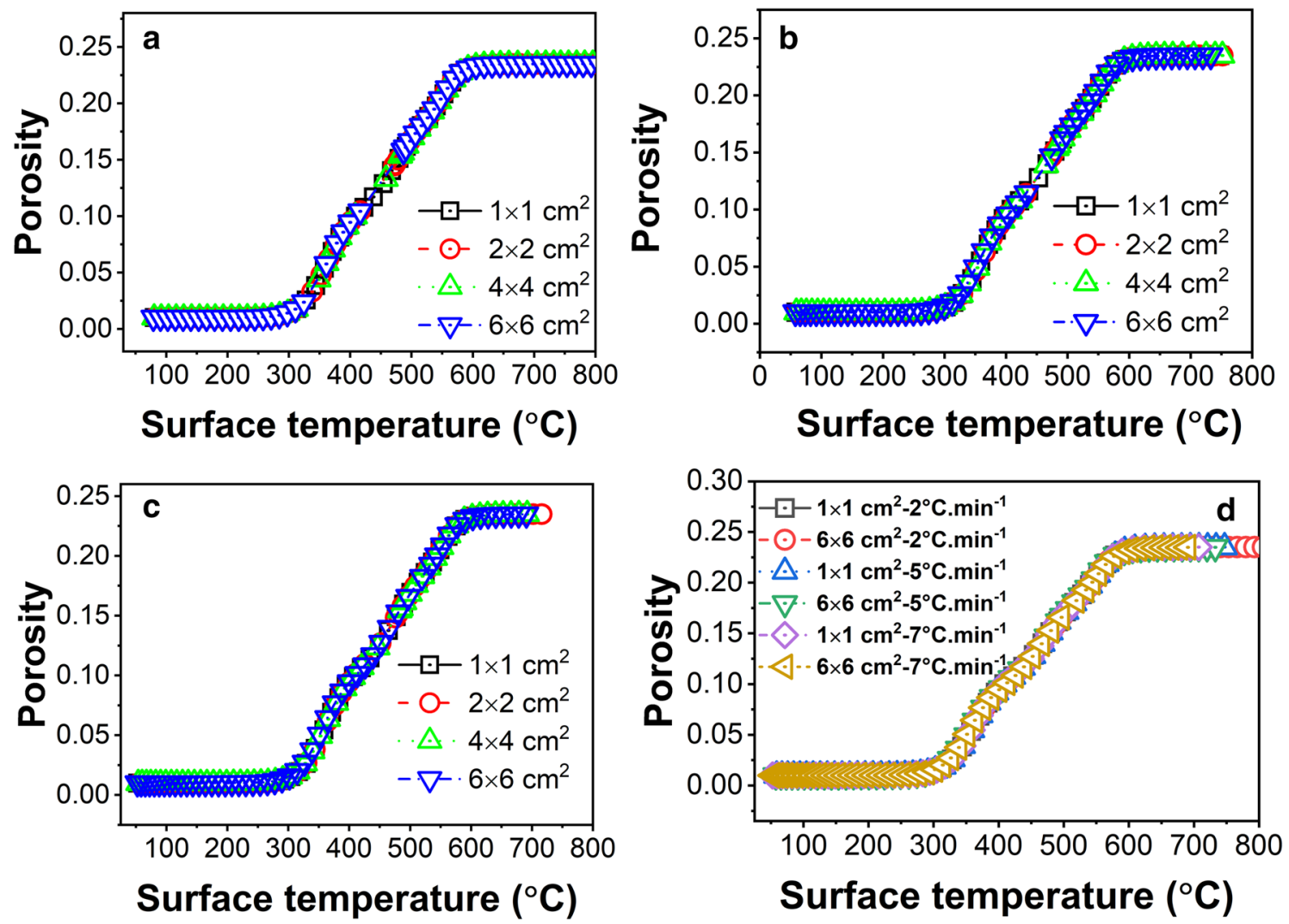

Fig. 7 Variation of porosity as a function of surface temperature for several sizes of samples at the heating rate of: $\mathbf{a} 2, \mathbf{b} 5, \mathbf{c} 7^{\circ} \mathrm{C} \mathrm{min}{ }^{-1}$ and d comparison of porosity at various heating rates

heated by convection and the gas flow was taken unidirectional while in the present model, the sample surface was in direct touch with the floor (surface) of the tubular furnace.

In order to understand the effect of size of the laminate on the maximum pressure buildup, the plots of maximum internal pressure $(\mathrm{Pmax} / \mathrm{Po})$ vs surface temperature for the laminates of various sizes $\left(1 \times 1,2 \times 2,4 \times 4\right.$ and $\left.6 \times 6 \mathrm{~cm}^{2}\right)$ and for the heating rate of $2{ }^{\circ} \mathrm{C} \mathrm{min}^{-1}$ are drawn as shown in Fig. 6a. The ratios of maximum pressure build-up to the atmospheric pressure of the laminates of $1 \times 1,2 \times 2$, $4 \times 4$ and $6 \times 6 \mathrm{~cm}^{2}$ sizes obtained are $6.4,14.2,30.1$ and 51.6 , respectively and the corresponding temperatures recorded are $310,312,315$ and $324^{\circ} \mathrm{C}$, respectively. In can be seen that the thick composites buildup high level of internal pressure because the generation of gas volume is significant, which may result in delamination or cracks formed in the composites. This result may be caused due to the amount of porosity produced during initial degradation in all samples is nearly same as shown in Fig. 7a, but the amount of gas produced is more for higher thickness sample. These temperatures are shifted towards the higher side and attributed to the presence of temperature gradient in the CCs.
Similar studies have been carried out at the heating rates of 5 and $7{ }^{\circ} \mathrm{C} \mathrm{min}^{-1}$ to understand the effect of heating rate on the maximum pressure buildup in the laminates during carbonization (Fig. $6 \mathrm{~b}$ and c). In these cases, also, the maximum pressure buildup within the samples exhibits dependency upon the thicknesses of the laminates. Thick composites generate the significant amount of internal pressure as explained before. The ratios of maximum pressure buildup (Pmax/Po) of these laminates $(1 \times 1$, $2 \times 2,4 \times 4$ and $\left.6 \times 6 \mathrm{~cm}^{2}\right)$ at the heating rate of $5{ }^{\circ} \mathrm{C} \mathrm{min}^{-1}$ are $6.3,14.4,28.7$ and 49.0 , respectively (Fig. $6 \mathrm{~b}$ ) and the corresponding temperatures are $315,316,340$ and $377^{\circ} \mathrm{C}$, respectively. Similarly, at the heating rate of $7^{\circ} \mathrm{C} \mathrm{min}^{-1}$, the ratios of maximum pressure buildup ( $\mathrm{Pmax} / \mathrm{Po})$ are 6.3, $14.3,28.5$ and 49.5 , respectively and the corresponding temperatures are $315,317,353$ and $413^{\circ} \mathrm{C}$, respectively (Fig. 6c). It can be said that for all heating rates, the maximum pressure created within the same size samples are nearly identical. This is anticipated due to the less porosity and low permeability of composite samples at the initial stage of carbonization. It is also observed that the pressure buildup remains constant over a wide range of surface temperature before and after the degradation temperature (Fig. 6). It can be observed that the peak of the Pmax/ 
Po is become broader as the heating rate is increased (Fig. 6a-c). Moreover, two peaks can be seen clearly in case of thick laminates $\left(6 \times 6 \mathrm{~cm}^{2}\right)$ for high heating rates (Fig. $6 \mathrm{~b}$ and c). The above consequences may be expected due to the increase in the temperature gradient. Therefore, the heating cycle used in the processing of CCs should be determined by considering the maximum pressure buildup and the temperature range. Otherwise, the high thermal gradient is developed inside the sample due to high heating rate, which consequently results in the development of undesirable internal stresses, damages, and warping in the composites. The adverse effects caused during the initial carbonization can be minimized by slow heating and isothermal heating of the samples. From Fig. $6 \mathrm{~b}$ and c, it can be seen clearly that $6 \times 6 \mathrm{~cm}^{2}$ laminate exhibit two distinguished peaks of maximum pressure build-up inside the laminate unlike the others samples having lower thickness. This can be attributed because of the high heating rate and high thickness of the laminate, the gases formed due to degradation of polymer matrix could not diffuse quickly that results high thermal gradients and high pressure build-up. This ultimately results two peaks of maximum pressure build-up in the degradation temperature range.

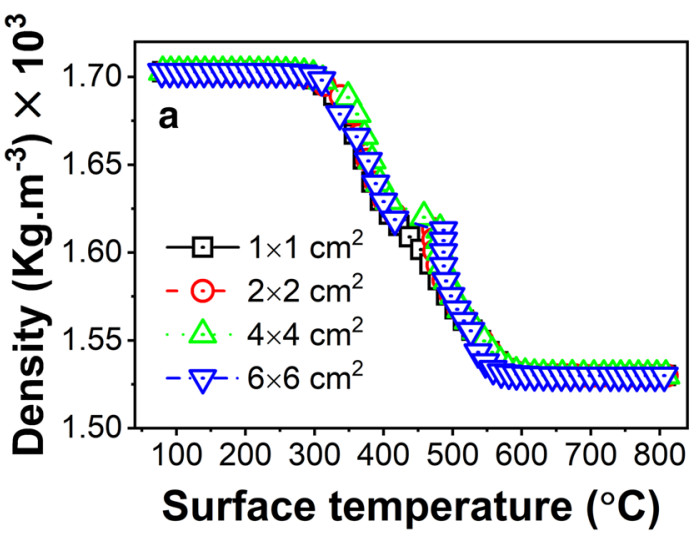

In order to verify the dependency of porosity of composite structure, the variation in porosity as a function of surface temperature is calculated and shown in Fig. 7a. Here the heating rate was kept at $2{ }^{\circ} \mathrm{C} \mathrm{min}^{-1}$. The increase in porosity enables the gases to flow out and decreases the pressure to the minimum level, and remains constant over the surface temperature range as depicted in Fig. 7a. At the beginning stage of degradation, the porosity is low (Fig. 3c). Upon further heating, the porosity increases linearly because of the weight loss of matrix in the form of gases (Fig. 2), and then the porosity remains constant [29]. It can also be seen from Fig. 7a-d that the porosity of the composites is almost un-affected by the increasing the heating rate $\left(2-7^{\circ} \mathrm{C} \mathrm{min}^{-1}\right)$.

Figure $8 \mathrm{a}$ exhibits the variation of density with respect to surface temperature at the heating rate of $2^{\circ} \mathrm{C} \mathrm{min}^{-1}$. At the beginning of carbonization, the density of the composite [calculated from Eq. (15)] obtained as $1702.93 \mathrm{~kg} \mathrm{~m}^{-3}$ remains constant for all samples. But the density decreases with increasing the temperature, because of increase in porosity reduces the density to $1530 \mathrm{~kg} \mathrm{~m}^{-3}$. The effect of heating rates $\left(5\right.$ and $\left.7{ }^{\circ} \mathrm{C} \mathrm{min}^{-1}\right)$ on the density of the specimens is also examined (Fig. $8 \mathrm{~b}$ and C). The similar results obtained as above, at the beginning of carbonization, the density of the composite obtained is $1702.93 \mathrm{~kg} \mathrm{~m}^{-3}$

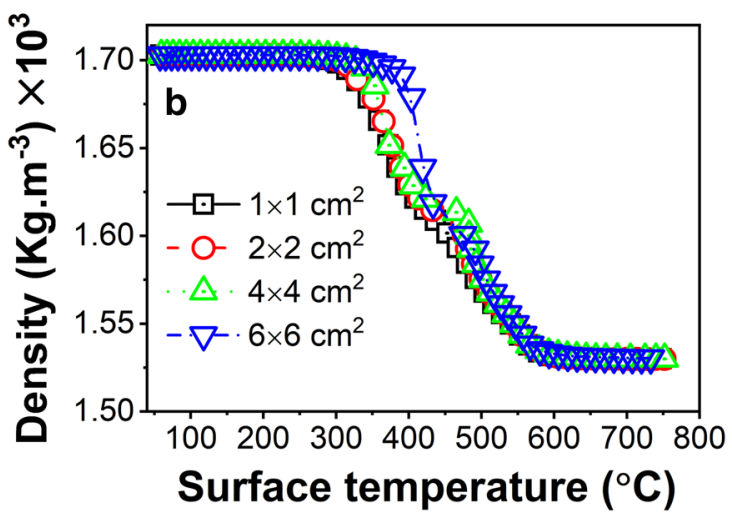

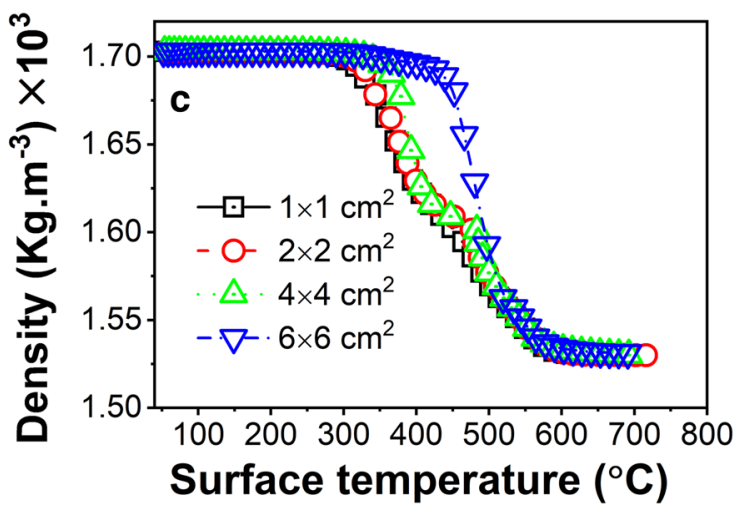

Fig. 8 Variation of density as a function of surface temperature for several sizes of samples at the heating rate of: a $2, \mathbf{b} 5$ and $\mathbf{c} 7^{\circ} \mathrm{C} \mathrm{min}{ }^{-1}$ 
and remained almost constant for all samples. As the surface temperature increases, the density of the composite decreases because of increase in the porosity level and then reaches to a minimum value of $\sim 1530 \mathrm{~kg} \mathrm{~m}^{-3}$ (this is again due to the constant porosity at this temperature range). It is also seen that the density trends are slightly different for $4 \times 4$ and $6 \times 6 \mathrm{~cm}^{2}$ samples when compared them at a heating rate of $2{ }^{\circ} \mathrm{C} \mathrm{min}{ }^{-1}$ (Fig. 8a). This may be due to the presence of temperature gradient within the samples. But the trend of porosity is same and independent of the sample size.

Since thermo-physical properties are dependent on the structure of the material $[17,18]$. Therefore, the amount of heat absorbed or released and transmission of thermal energy (conductivity) during carbonization depends on the microstructure of raw materials i.e. the type of fiber and matrix present in the composites and structural arrangements of the two and also on the cracks, defects, and voids present in the composite structure. Herein, the thermo-physical properties during initial carbonization were studied. The specific heat $\left(c_{s}\right)$ of composites was evaluated using Eq. (17). It is observed that during initial stage of carbonization, the $c_{s}$ increased to the maximum value of $1710 \mathrm{~J} \mathrm{~kg}^{-1} \mathrm{~K}^{-1}$ and remained constant till the surface temperature is enough to increase the porosity in the samples. The increase of $c_{s}$ is due to the entrapment of decomposed gases within the structure. This is again attributed to the minimum porosity and permeability of porous composite at the initial stage. Upon further heating, the increase in porosity of composite structure decreases the heat capacity and follows their own density trends as shown in Fig. 9a. The decrease in the specific heat is due to the gas flow, which takes the energy out through the heat convection. Once, the surface temperature crosses at $727^{\circ} \mathrm{C}$, the $c_{s}$ values again increase. This consequences because of increase in the heat capacity of carbon fibers as mentioned in Eq. (20). Similarly, the $c_{s}$ of other samples having the different sizes $\left(4 \times 4\right.$ and $\left.6 \times 6 \mathrm{~cm}^{2}\right)$ is also studied. No significant difference is observed. The $c_{s}$ of composites was also evaluated at the other heating rates of 5 and $7{ }^{\circ} \mathrm{C}$ min $^{-1}$ (Fig. $9 \mathrm{~b}$ and C). The $c_{\mathrm{s}}$ depends on the sample size, which follows similar trend as density for both the heating rates i.e., 5 and $7{ }^{\circ} \mathrm{C} \mathrm{min}^{-1}$ (Fig. $8 \mathrm{~b}$ and $\mathrm{C}$ ).

The in-plane thermal conductivity $\left(\mathrm{k}_{\mathrm{x}}\right)$ of the composite was evaluated using Eq. (25). In 2D composite, the thermal conductivity along the fiber direction is higher than in the perpendicular direction. Figure 10a shows the variation of $\mathrm{K}_{\mathrm{x}}$ as a function of surface temperature for the samples of
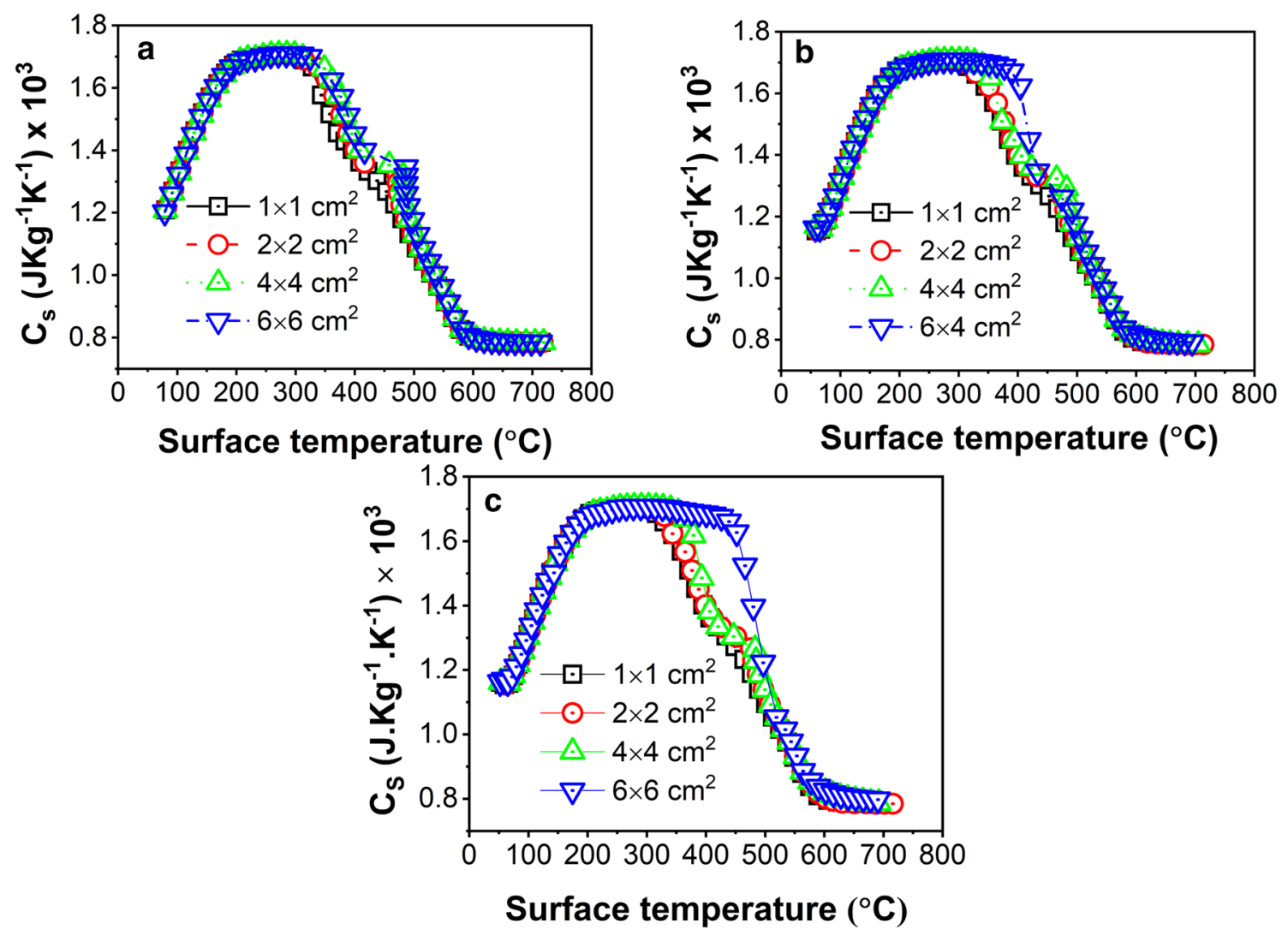

Fig. 9 Variation of specific heat $\left(c_{s}\right)$ as a function of surface temperature for several sizes of samples at the heating rate of: $\mathbf{a} 2, \mathbf{b} 5$ and $\mathbf{c}$ $7^{\circ} \mathrm{C} \mathrm{min}^{-1}$ 

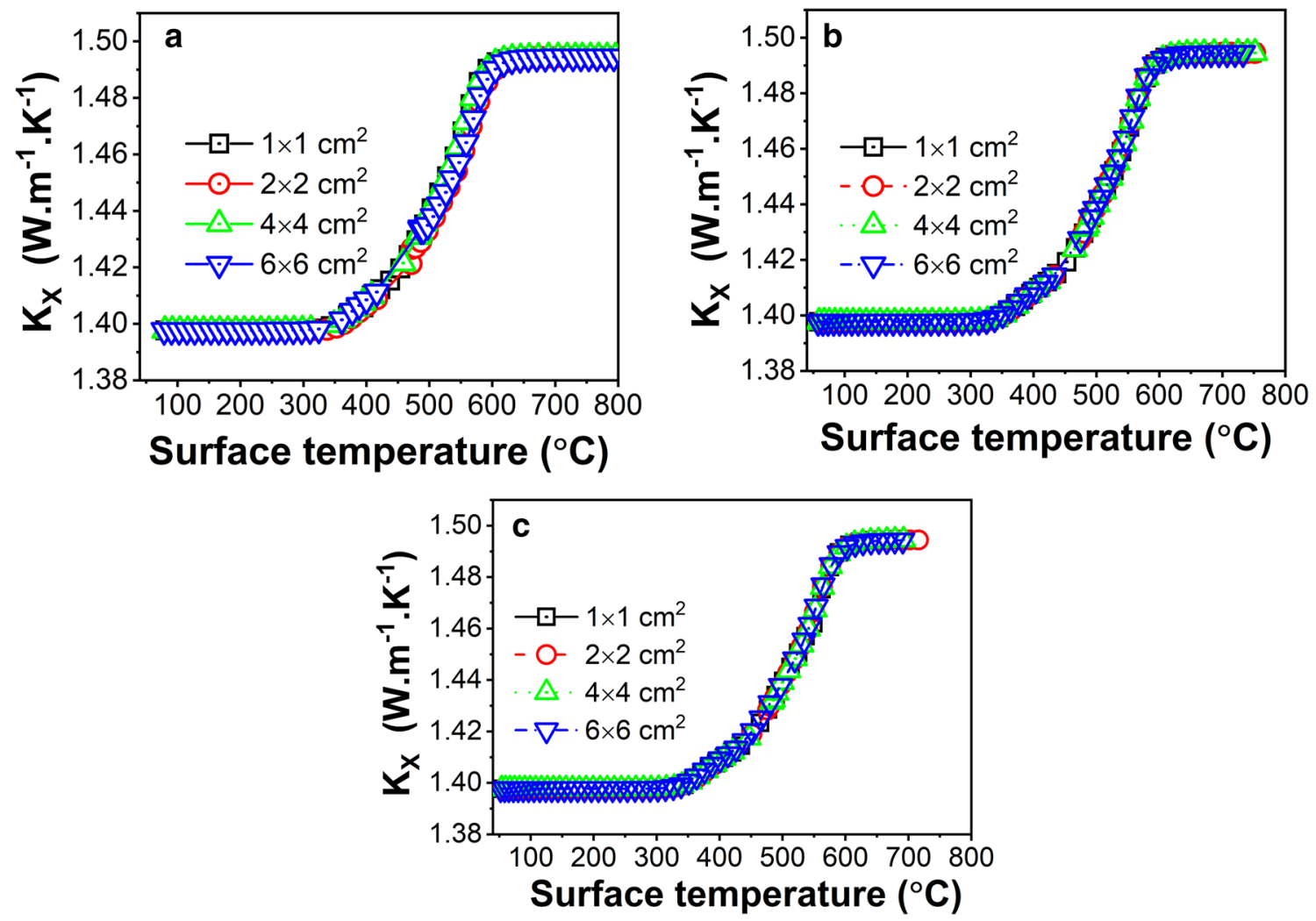

Fig. 10 Variation of in-plane thermal conductivity $\left(\kappa_{\mathrm{x}}\right)$ as a function of surface temperature for several sizes of samples at the heating rate of: a 2, b 5 and $\mathbf{c} 7{ }^{\circ} \mathrm{C} \mathrm{min}^{-1}$

various thicknesses at the heating rates of $2^{\circ} \mathrm{C} \min ^{-1}$. At the beginning of carbonization, the $\mathrm{K}_{\mathrm{x}}$ is same for all samples i.e., $1.3977 \mathrm{~W} \mathrm{~m}^{-1} \mathrm{~K}^{-1}$ and independent of the sample thickness. Upon further heating, the increase in $\mathrm{K}_{\mathrm{x}}$ is seen and followed their respective porosity trends (Fig. 7a) and reached to the maximum value of $1.4945 \mathrm{~W} \mathrm{~m}^{-1} \mathrm{~K}^{-1}$ for all samples. Because of the increase in porosity and permeability of the composite that is the result of the removal of gases owing to the degradation of the matrix. Simultaneously, the gas flow brings the thermal energy out by heat convection. Moreover, as surface temperature increases the thermal conductivity of carbon fibers also increase. The combined effect of both the heat transfer through convection and the increment in the thermal conductivity of carbon fiber results the increases the in-plane thermal conductivity of the composite. No difference in the $\mathrm{k}_{\mathrm{x}}$ is noticed for the heating rate of 5 and $7{ }^{\circ} \mathrm{C} \mathrm{min}^{-1}$ (Fig. 10b and c)

Similarly, the variation of through thickness thermal conductivity $\left(\mathrm{k}_{\mathrm{y}}\right)$ with respect to surface temperature for the composite of various thicknesses at the heating rate of 2, 5 and $7{ }^{\circ} \mathrm{C} \mathrm{min}^{-1}$ was evaluated using Eqs. (23) and (24) (Fig. 11a-c). At the beginning of carbonization, maximum $\mathrm{K}_{\mathrm{y}}$ obtained is $0.8981 \mathrm{~W} \mathrm{~m}^{-1} \mathrm{~K}^{-1}$ for all samples. When the composite is heated further, a decrement in $\mathrm{K}_{\mathrm{y}}$ is observed. This trend is similar to the respective variation trend in density as demonstrated in Fig. 8 and further $\mathrm{K}_{\mathrm{y}}$ is reached to the minimum value of $0.694 \mathrm{~W} \mathrm{~m}^{-1} \mathrm{~K}^{-1}$ for all samples. The decrease in the through thickness conductivity of the composite is because of the low thermal conductivity of carbon fibers in the perpendicular direction and presence of cylindrical pores in the carbon fibers, which are elongated in the fiber direction [31,32]. Similar trends in the variation of $\mathrm{k}_{\mathrm{y}}$ are observed for other heating rates of 5 and $7^{\circ} \mathrm{C}$ min $^{-1}$ as depicted in Fig. $11 \mathrm{~b}$ and $\mathrm{c}$.

\section{Conclusions}

The carbonization behavior of composite was studied by blending heat, mass and momentum transport equations with weight loss kinetics. Then, the 2-D finite difference method (FDM) was employed to solve the governing equations for the flow of gases during carbonization. Furthermore, the effects of heating rate and composite size on the pressure, porosity, density, specific heat and thermal conductivity distributions with respect to surface temperature were investigated. The results obtained 

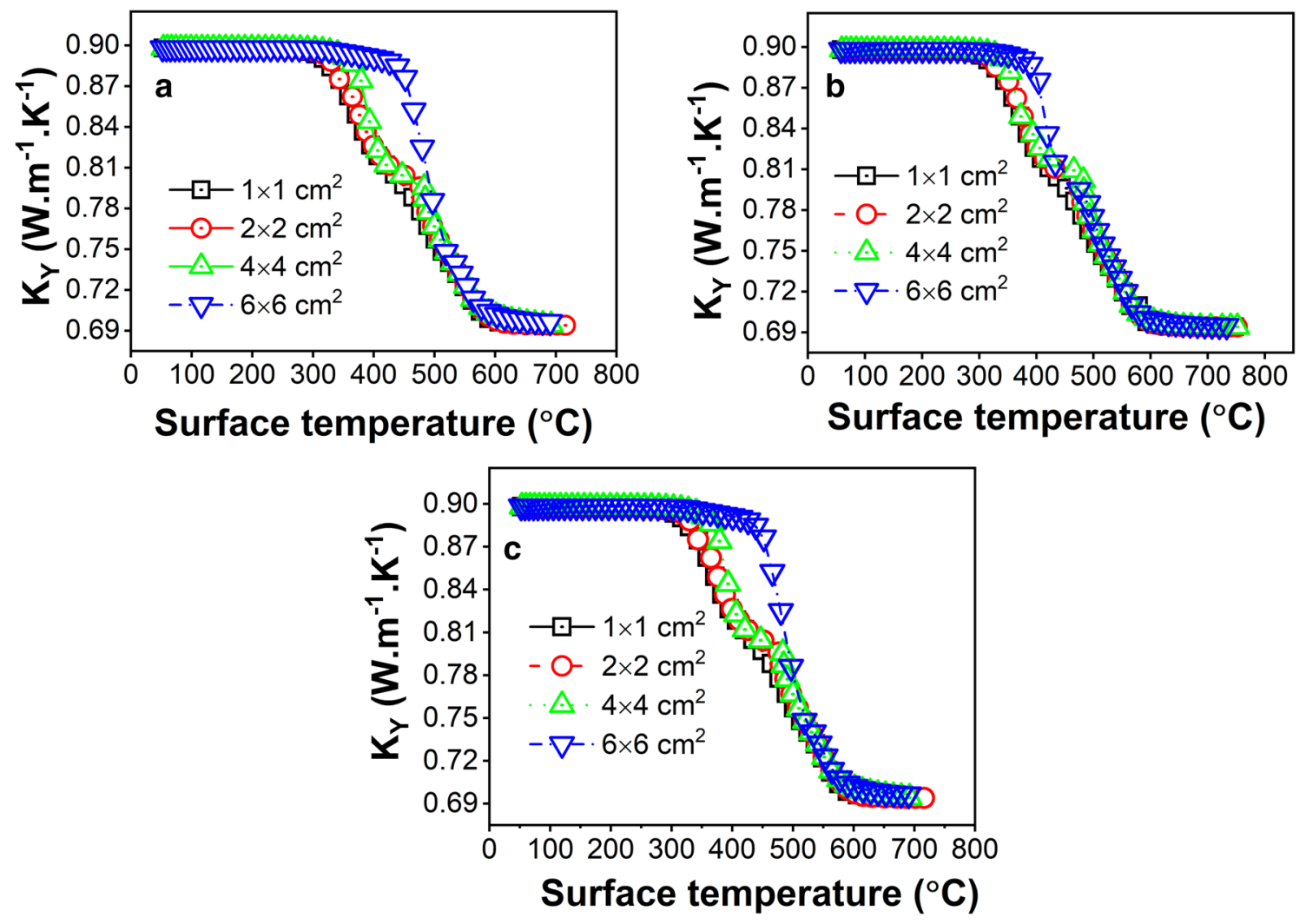

Fig. 11 Variation of through-thickness thermal conductivity $\left(\mathrm{k}_{\mathrm{y}}\right)$ as a function of surface temperature for several sizes of samples at the heating rate of: a $2, \mathbf{b} 5$ and $\mathbf{c} 7^{\circ} \mathrm{C} \mathrm{min}^{-1}$

reveals that at any heating rate, the maximum pressure developed depends upon the size of the composite laminate. The significant internal pressure is generated in thick composite which may result in delamination or cracks in the composite. The high heating rate results in large temperature gradients within the composite, which may lead to non-homogeneity and undesirable deformations in the composites. Furthermore, these adverse effects may affect the processing cycles and quality of the composites. To minimize this effect, the processing steps (slow heating rate) can be used as guidelines for processing of CCs. Moreover, it is also established from the model that the properties of composite such as density, specific heat and thermal conductivity dependent only on the temperature and independent on heating rates and size of samples.

Funding The authors acknowledge the financial support provided by Department of Atomic Energy, India for carrying out this research work.

\section{Compliance with ethical standards}

Conflict of interests The authors declare that they have no conflict of interests.

\section{SN Applied Sciences}

\section{References}

1. Fitzer E, Manocha LM (1998) Carbon reinforcements and carbon/ carbon composite. Springer, Berlin

2. Kar KK (2016) Composite materials: processing, applications, characterizations. Springer, Heidelberg

3. Nam JD, Seferis SC (1992) Initial polymer degradation as a process in the manufacture of carbon-carbon composites. Carbon 30(5):751-761

4. Trick KA, Saliba TE (1995) Mechanisms of the pyrolysis of phenolic resin in a carbon/phenolic composite. Carbon 33(11):1509-1515

5. Trick KA, Saliba TE, Sandhu SS (1997) A kinetic model of the pyrolysis of phenolic resin in a carbon/phenolic composite. Carbon 35(3):393-401

6. Dimitrienko Y (1997) Thermomechanical behaviour of composite materials and structures under high temperatures: 1 materials. Compos Part A 28A:453-461

7. Dimitrienko Y (1997) Modelling of the mechanical properties of composite materials at high temperatures: part 1. Matrix and fibers. Appl Compos Mater 4:219-237

8. Dimitrienko Y (1998) Modelling of the mechanical properties of composite materials at high temperatures. Part 3. Textile composites. Appl Compos Mater 5:257-272

9. Heinrich C, Aldridge M, Wineman AS, Kieffer J, Waas AM, Shahwan KW (2013) The role of curing stresses in subsequent response, damage and failure of textile polymer composites. J Mech Phys Solids 61:1241-1264 
10. Yin T, Wang $Y$, He L, Gong X (2017) Stress and damage development in the carbonization process of manufacturing carbon/ carbon composites. Comput Mater Sci 138:27-33

11. Kuo HH, Chernlin JH, Ju CP (2005) Effect of carbonization rate on the properties of a PAN/phenolic-based carbon/carbon composite. Carbon 43:229-239

12. Ko TH, Chen PC (1991) Study of the pyrolysis of phenolic resin reinforced with two-dimensional plain woven carbon fabric-I. J Mater Sci Lett 10:301-303

13. Chang WC, Ma CCM, Tai NH, Chen CB (1994) Effects of processing methods and parameters on the mechanical properties and microstructure of carbon/carbon composites. J Mater Sci 29:5859-5867

14. Chlopek L, Blzewcz S (1991) Effect of processing variables on the properties of carbon-carbon composites. Carbon 29(2):127-131

15. Lovell AB, Brezinsky K, Glassman I (1989) The gas phase pyrolysis of phenol. Int J Chem Kinet 21:547-560

16. Sullivan EA (1991) Thermal degradation of epoxy novolacphenol formaldehyde novolac resin systems. J Appl Polym Sci 42:1815-1827

17. Lachaud J, Vignoles GL (2009) A Brownian motion technique to simulate gasification and its application to $\mathrm{C} / \mathrm{C}$ composite ablation. Comput Mater Sci 44(4):1034-1041

18. Yin T, Zhang Z, Li X, Feng X, Feng Z, Wang Y, He L, Gong X (2014) Modeling ablative behavior and thermal response of carbon/ carbon composites. Comput Mater Sci 95:35-40

19. Zhang B, Li X (2018) Numerical simulation of thermal response and ablation behavior of a hybrid carbon/carbon composite. Appl Compos Mater 25:675-688

20. Zhang B, Li X (2018) Thermal response of a 4D carbon/carbon composite with volume ablation: a numerical simulation study. Appl Compos Mater 25:191-202

21. Riccio A, Damiano M, Zarrelli M, Giordano M, Scaramuzzino F (2014) Simulating the response of composite plates to fire. Appl Compos Mater 21:511-524

22. Wang H, Cao M, Siddique A, Sun B, Gu B (2017) Numerical Analysis of thermal expansion behaviors and interfacial thermal stress of 3D braided composite materials. Comput Mater Sci 138:77-91
23. Shigang A, Hailong F, Rujie H, Yongmao P (2015) Multi-scale modeling of thermal expansion coefficients of $\mathrm{C} / \mathrm{C}$ composites at high temperature. Mater Des 82:181-188

24. Shigang $A$, Rujie $H$, Yongmao $P$ (2015) A numerical study on the thermal conductivity of $3 \mathrm{D}$ woven $\mathrm{C} / \mathrm{C}$ composites at high temperature. Appl Compos Mater 22:823-835

25. Wang L, Wub J, Chen C, Zheng C, Li B, Joshi SC, Zhou K (2017) Progressive failure analysis of 2D woven composites at the meso-micro scale. Compos Struct 178:395-405

26. Kim J, Lee WI, Lafdi K (2003) Numerical modeling of the carbonization process in the manufacture of carbon/carbon composites. Carbon 41:2625-2634

27. Ravikumar NL, Kar KK, Pandya C, Sathiyamoorthy D (2011) Numerical simulation of the degradation behavior of the phenolic resin matrix during the production of carbon/carbon composites. Fuller Nanotub Carbon Nanostruct 19:1-20

28. Bromely LA, Wilke CR (1951) Viscosity behavior of gases. Ind Eng Chem 43(7):1641-1648

29. Mottram JT, Taylor R (1987) Thermal conductivity of fibre-phenolic resin composites. I Thermal diffusivity measurements. Compos Sci Technol 29:189-210

30. Mottram JT, Taylor R (1987) Thermal conductivity of fibre-phenolic resin composites Part II: Numerical evaluation. Compos Sci Technol 29:211-232

31. Manocha LM, Warrier A, Manocha S, Sathiyamoorthy D, Banerjee $S$ (2006) Thermophysical properties of densified pitch based carbon/carbon materials-I. Unidirectional composites. Carbon 44:480-487

32. Manocha LM, Warrier A, Manocha S, Sathiyamoorthy D, Banerjee $S$ (2006) Thermophysical properties of densified pitch based carbon/carbon materials-II. Bidirectional composites. Carbon 44:488-495

Publisher's Note Springer Nature remains neutral with regard to jurisdictional claims in published maps and institutional affiliations. 